Original Research Paper

\title{
Fuelwood Consumption and its Impact on Forests in the Teknaf Peninsula on the Southern Coast of Bangladesh
}

\author{
Ullah SM Asik and Tani Masakazu \\ Department of Environmental Design, Kyushu University, Fukuoka, Japan
}

\author{
Article history \\ Received: $20-02-2017$ \\ Revised: 24-04-2017 \\ Accepted: 24-05-2017 \\ Corresponding Author: \\ Ullah SM Asik \\ Department of Environmental \\ Design, Kyushu University, \\ Fukuoka, Japan \\ Email: mt18916@gmail.com
}

\begin{abstract}
This study focuses on the household fuelwood in the Teknaf Peninsula of Bangladesh. Teknaf Peninsula has a protected forest area which is facing the threat of extinction due to the over dependency of the local people. Among the subsistence activities, harvesting fuelwood from the protected forest area is the most common and also a significant cause for the deforestation. This study aimed to determine the household fuelwood consumption and factors influencing the consumption. Data was collected during March 2015 using structured questionnaire to interview the sampled households. Among the 42 households the average annual consumption of fuelwood per person was found $1168 \mathrm{~kg}$, which is quit higher than other similar studies around the world. Among the considered factors only family size influenced the fuelwood consumption. According to the current reports and our fuelwood consumption study the forest is not capable to provide fuelwood in a sustainable way.
\end{abstract}

Keyword: Fuelwood, Forest, Family Size, GHGs

\section{Introduction}

Over three billion people of the world lives in rural areas (World Bank, 2015) with inadequate supply of energy for cooking, lighting, heating, transportation and other purposes. Worldwide, 1.4 billion people have limited access to electricity and 2.7 billion people rely on biomass fuel, mostly in rural areas (IEA, 2010). People in rural areas tend to have relatively low income and are more reliant on natural resources. For these reasons, rural energy development is a critical global need that can save time, improve health and help preserve the environment (Bond and Sun, 2005; Jetter and Kariher 2009; Madubansi and Shackleton, 2006; Ramanathan and Carmichael, 2008; Sovacool and Drupady, 2011).

Among rural energy issues, fuel for cooking is the most important and has significant environmental consequences. According to the World Health Organization, almost $70 \%$ of households in developing countries use organic fuels, such as wood, dung and crop residue for cooking (WHO, 2006) and a major proportion of cooking fuel comes from wood known as 'fuelwood'. Fuelwood accounts for over 54\% of all global wood harvested per annum (Osei, 1993). In the post-industrial era, the world is dealing with climate change and so forest degradation is a major concern. The consumption of biomass as fuel has been identified as one of the most significant causes of forest decline in many developing countries (Bhatt and Sachan, 2004). Environmental damage from fuelwood harvesting can be significant if too many people depend on too few forested areas. Many hotspots of biodiversity in the tropics (Bouget et al., 2012; Myers et al., 2000) represent such a scenario, with numerous human populations relying on vanishing, reducing and fragmenting forests to meet their demand for fuelwood, land for agriculture and ingestion of animal protein (Peres et al., 2010; Ruger et al., 2008).

Industrialization, encroachment into forests and wood trading are considered as the major large-scale threats to forests. However, small-scale disturbance, such as fuelwood harvesting is comparatively ignored and there is a lack of knowledge regarding its impact on forests. Bangladesh is one of the most vulnerable countries to climate change, where forest lands have shrunk at an alarming rate during the last few decades. There is a lack of research regarding the impact of fuelwood harvesting on deforestation in Bangladesh, where a large portion of the population depends on solid fuelsand a substantial amount of this is fuelwood from forests. Consumption and demand are very important for understanding the impact of fuelwood on forests; however, this understanding has always been hampered by a lack of reliable information. It is seldom reported that the greater part of consumption in rural areas is by poor households. 
Consequently, is has been difficult to determine the magnitude of fuelwood use and itsimpacts on forests and rural livelihoods (Arnold and Persson, 2003).

This study focuses on household fuelwood consumption in Teknaf Upazila, a district of Cox's Bazar in southern Bangladesh. In Teknaf, there is a protected forest known as Teknaf Wildlife Sanctuary covering 11,615 ha and it is the main source of fuelwood for 260,000 people (BBS, 2011). Due to poverty, lack of awareness and no alternatives for fuel, people in Teknaf solely depend on this protected forest for fuelwood. Large-scale wood resource consumption other than fuelwood is not prominent in this area and the forest has decreased by nearly $45 \%$ during the last two decades (CGEIS, 2011), with fuelwood harvesting having a large role in forest degradation. An estimation of household fuelwood consumption gives an idea of domestic fuelwood demand and analysis of consumption against socioeconomic characteristics suggests possible factors that affect the consumption. Although approximate, this is a useful initial approach and will have potential applications in designing sustainable uses of forest resources to ensure conservation of forest in Teknaf.

This study aims to (a) quantify the Household ( $\mathrm{HH})$ fuelwood consumption, (b) describe the socioeconomic characteristics of $\mathrm{HHs}$ and their relationship with fuelwood consumption and (c) estimate the impact of fuelwood harvesting on the forest and climate.

\section{Materials and Methods}

\section{A. Study Area}

The study took place in the Jahajpura village of Teknaf Upazila (Upazila is an administrative unit of local government), part of Cox's Bazar District (Fig. 1). The Teknaf Peninsula in which Teknaf Upazila is located lies in the south-eastern corner of Bangladesh bordering Myanmar on the east and facing the Bay of Bengal on the west. The Teknaf Peninsula is a narrow peninsula running north-south and occupies the westernmost part of the Arakan Range with low-lying hills of elevation 200-300 m on its north-south axis (Tani et al., 2011). The area is characterized by subtropical climate with a temperature range between 15 and $32^{\circ} \mathrm{C}$ in winter (January) and summer (May), respectively. The mean annual rainfall is around $4000 \mathrm{~mm}$ and $83 \%$ of rainfall occurs during the monsoon season of June-August (BMD, 2014). The forest in Teknaf Peninsula was designated by the Government of Bangladesh as an Ecologically Critical Area in 1983 (Alam et al., 2012) because reduction in biodiversity was an evident problem. The region is also culturally and economically distinctive in Bangladesh. It has a dense poor population facing problems of illegal migrants and gradual reduction of natural resources due to constant shrinkage of forest during the last few decades and is highly vulnerable to climate change. Jahajpura is a village in the western side of the peninsula stretching from the sea to the hilly forest behind.

\section{B. Methods}

The focus of this study was to determine fuelwood consumption and to describe the socioeconomic factors affecting it. Data were collected through a HH survey. Among $470 \mathrm{HHs}$ of Jahajpura, $42 \mathrm{HHs}$ were interviewed using a structured questionnaire. In order to determine HHs to be studied, they were categorized into three groups based on family size: Small (upto five members), medium (6-10 members) and large families (more than 10 members). Then sample HHs were drawn by a stratified random sampling. From each category, $14 \mathrm{HHs}$ were selected, making a total sample size of 42 . Data were collected during January-March 2015.

To estimate fuelwood consumption, sample HHs were asked to show stacked fuelwood bundles for $\mathrm{HH}$ cooking. From the bundles (shown in Fig. 2), based on the family size, 3-5 bundles were weighed and separated from the rest of the fuelwood. Then the respondents were requested to cook for the $\mathrm{HH}$ from the weighed bundles for the next $3 \mathrm{~d}$. After $3 \mathrm{~d}$, the remaining bundles were weighed again. After physically weighing of fuelwood, it was divided by family size to determine per capita consumption. Three days were selected to minimize factors such as cooking time, guest appearance and heavy meal cooking. Different sources of fuelwood were listed with their percentage of contribution.

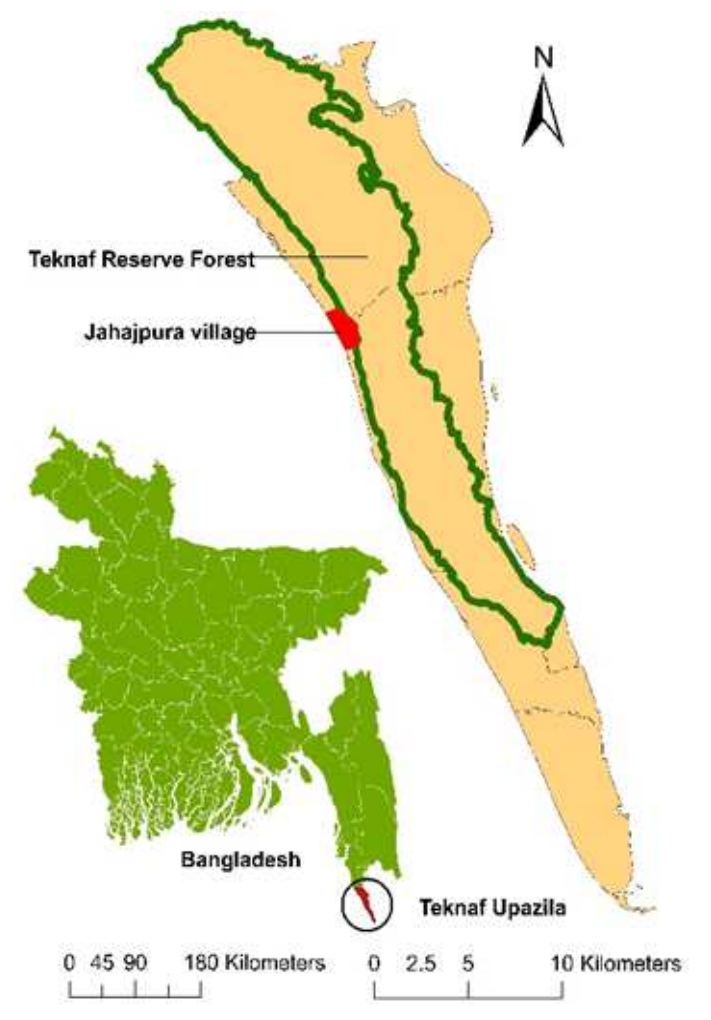

Fig. 1. Study area in Teknaf Peninsula 


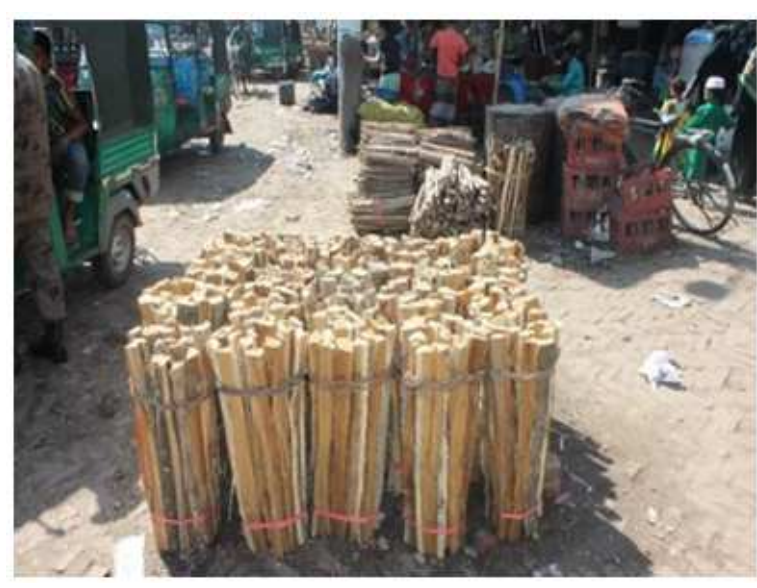

(a)

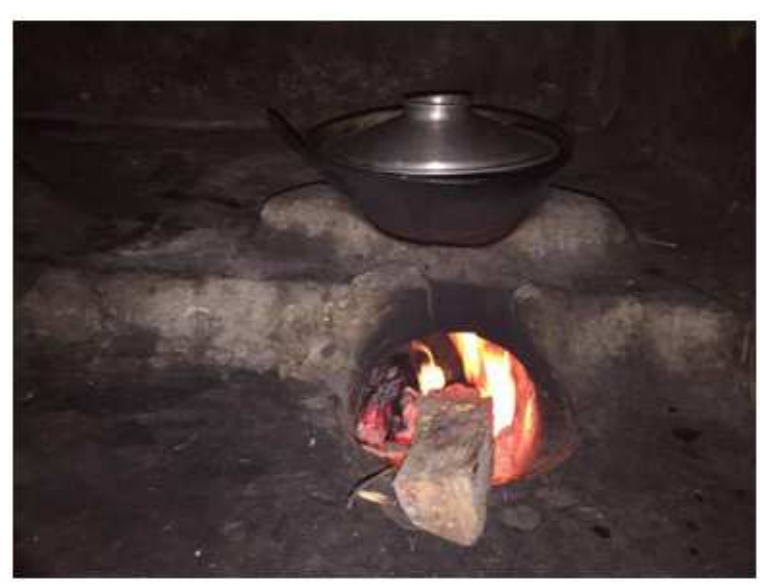

(b)

Fig. 2. Fuelwood bindles (a) and using fuelwood in traditional stoves (b)

Table 1. Fuelwood consumption according to family size and their source

\begin{tabular}{llll}
\hline Categories & $\begin{array}{l}\text { Daily household fuelwood } \\
(\mathrm{kg}) \text { consumption }( \pm \mathrm{SD})\end{array}$ & $\begin{array}{l}\text { Daily per capita fuelwood } \\
(\mathrm{kg}) \text { consumption }( \pm \mathrm{SD})\end{array}$ & $\begin{array}{l}\% \text { of fuelwood } \\
\text { from forest }\end{array}$ \\
\hline Small family & $13( \pm 4.5)$ & $4.2( \pm 0.3)$ & 66 \\
Medium family & $21( \pm 5.1)$ & $2.9( \pm 0.6)$ & 68 \\
Large family & $34( \pm 2.6)$ & $2.6( \pm 3.3)$ & 55 \\
Total & $23( \pm 9)$ & $3.2( \pm 2.0)$ & 63 \\
\hline
\end{tabular}

Table 2. Perception regarding fuelwood extraction and environment degradation

\begin{tabular}{|c|c|c|c|}
\hline \multirow[b]{2}{*}{ Statement } & \multicolumn{3}{|c|}{ Nature of opinion } \\
\hline & $A^{*}$ & $U^{*}$ & $D^{*}$ \\
\hline Excessive fuelwood collection is destroying the forest & 7 & 23 & 12 \\
\hline After a certain period forest will become unable to supply fuelwood & 13 & 19 & 10 \\
\hline Cutting saplings does not harm the forest & 15 & 14 & 13 \\
\hline Planting indigenous trees will help the forest & 19 & 21 & 2 \\
\hline Restriction on excessive fuel wood extraction is good for forest & 11 & 20 & 11 \\
\hline Inside the forest all large trees should be harvested & 7 & 22 & 13 \\
\hline Increasing homestead fuelwood production can reduce pressure on forest & 21 & 14 & 7 \\
\hline
\end{tabular}

\section{*A = Agree, $\mathrm{U}=$ Undecided, $\mathrm{D}=$ Disagree}

The age, education and perception regarding fuelwood extraction and environment degradation of the HH head were documented. Duration of residence, area, annual income and family size of the $\mathrm{HH}$ were recorded. Annual income of each $\mathrm{HH}$ was separately recorded in different categories such as farming, fishing labor, abroad and business. Perception regarding fuelwood extraction and environment degradation was determined by perception score using Likert scale. The Likert scale is a measure of attitudes, preferences and subjective reactions by eliciting a response along the lines of strength of agreement with the scale items (Likert, 1932). Here perception score was calculated by plotting seven statements (Table 2) regarding fuelwood extraction and environmental degradation against a three-point scale: 'agree', 'undecided' and 'disagree', weighted as 3,2 and 1, respectively. The score of seven statements was summed to calculate the perception score of every $\mathrm{HH}$ head. Perception scores regarding fuelwood extraction and environment degradation were in the range of 7-21: score 7-11 was assumed to indicate unfavorable perception; $12-16$ to indicate neutral perception; and 17-21 to indicate favorable perception. Socioeconomic characteristics influence human activities to varying degrees-socioeconomic factors and their relationship with fuelwood consumption were explored using correlation and linear regression analyses. Pearson' sproduct-moment correlations were used to identify socioeconomic factors influencing fuelwood consumption and linear regressions were calculated to determine the extent of their influence on fuelwood consumption. Previous records of forest degradation and population increase in the Teknaf Peninsula were used to describe the impact of fuelwood collection on the local forests. 


\section{Results}

\section{A. Fuelwood Consumption and Source}

All 42 assessed HHs reported using fuelwood regularly as their only source of cooking fuel. The fuelwood consumption of each group of $\mathrm{HHs}$ categorized by family size is presented in Table 1 . The overall mean of daily per capita fuelwood consumption was $3.2 \mathrm{~kg}$ (1168 kg/person/year). The $\mathrm{HH}$ fuelwood consumption increased as family size increased: 13, 21 and $34 \mathrm{~kg}$ for small, medium and large families, respectively. However, the per capita fuelwood consumption decreased with increased family size. The highest fuelwood consumption per day per $\mathrm{HH}$ was $37.25 \mathrm{~kg}$ (14 family members) and the lowest was $6.92 \mathrm{~kg}$ (two members).

The HHs reported a mean of $63 \%$ of fuelwood from forest and $37 \%$ from homesteads. However, this was not directly measured and relied on estimates from the respondents. Among HHs, the large HHs had the highest percentage of fuelwood from homesteads $(45 \%)$. Figure 3 shows the fuelwood consumption pattern due to its source of collection. The sources of fuelwood were forest and homestead. We categorized the HHs into three groups based on the fuelwood collection from forest: $<30 \%, 30-60 \%$ and $>60 \%$.
The consumption of fuelwood from forest was in the range of $3.0-3.7 \mathrm{~kg} /$ person/day.

\section{B. Socioeconomic Characteristics}

Socioeconomic characteristics of $\mathrm{HHs}$ are shown in Table 3. The meanage of $\mathrm{HH}$ heads was 34.3 years and their mean years of schooling was 2.07. Among the groups, the small family group had the youngest $\mathrm{HH}$ heads (27.5 years) with the highest level of schooling (3.4 years). Mean annual income of HHs was nearly 411,000 BDT. The large family group had the highest annual income $(668,000$ BDT), which was about three times that of the small family group. The mean family size was 5.3 persons and mean area of homesteads was 0.29 ha. The mean duration of residence in the current location was 32.7 years, with the group of small families more recent than the medium and large families. Perception score towards fuelwood extraction and environmental degradation had a mean of 15.57 and range of 7-21.

\section{Factors Affecting Fuelwood Consumption}

Table 4 shows the Pearson's product-moment correlation coefficients (r) between fuelwood consumption and socioeconomic characteristics of HHs. Family size was negatively correlated with fuelwood consumption $(\mathrm{r}=$ $-0.552, \mathrm{p}<0.01$ ) with $1 \%$ level of significance.

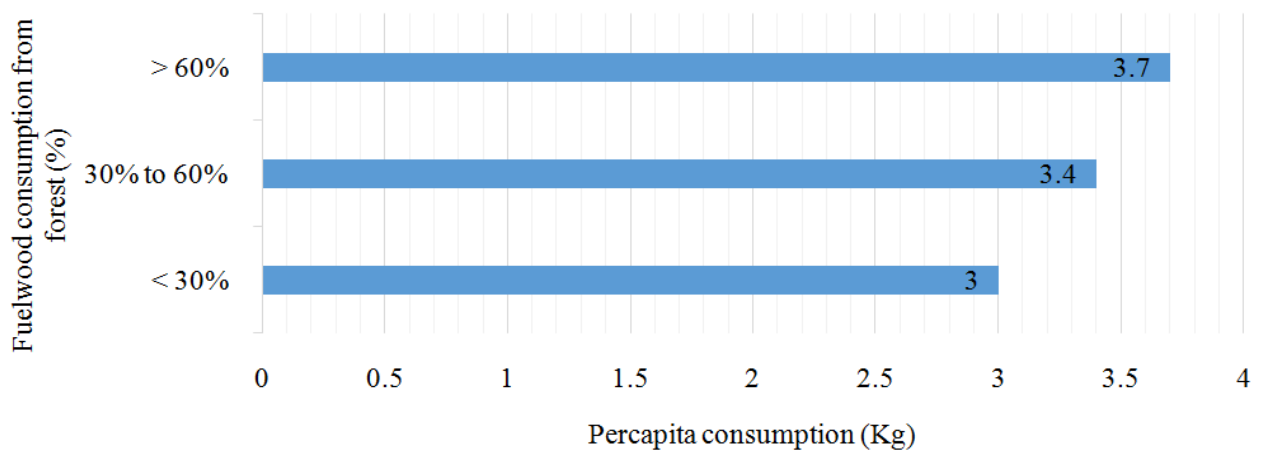

Fig. 3. Fuelwood consumption according to source

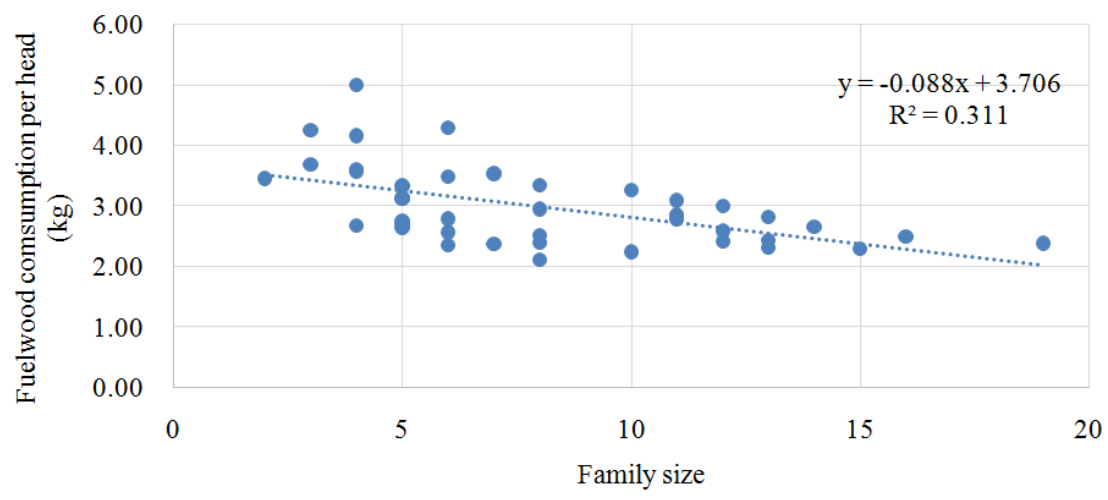

Fig. 4. Relationship between family size and fuelwood consumption 
Table 3. Socioeconomic characteristics profile

\begin{tabular}{lcrrr}
\hline & Small $(\mathrm{n}=14)$ & Medium $(\mathrm{n}=14)$ & Large $(\mathrm{n}=14)$ & Total $(\mathrm{n}=42)$ \\
\hline Age & 27.50 & 33.20 & 42.90 & 34.30 \\
Education (schooling years) & 3.40 & 2.40 & 0.35 & 2.07 \\
Income (000 BDT) & 209.00 & 374.00 & 668.00 & 411.00 \\
Family size (members) & 4.20 & 7.60 & 13.20 & 5.30 \\
Homesteadsize (ha) & 0.24 & 0.30 & 0.35 & 0.29 \\
Time of residence (years) & 25.00 & 36.80 & 35.20 & 32.70 \\
Perception score(range 7-21) & 15.20 & 15.10 & 14.90 & 15.10 \\
\hline
\end{tabular}

Table 4. Pearson's product-moment correlations

\begin{tabular}{lllll}
\hline & & Tabulated r values with $40 \mathrm{df}$ \\
& Variables & $\begin{array}{l}\text { Pearson's product-moment } \\
\text { correlation coefficient (r) }\end{array}$ & 0.05 level & 0.01 level \\
\hline Per capita daily & Age & 0.246 & 0.257 & 0.358 \\
fuelwood & Annual Income & 0.183 & & \\
consumption & Homestead Area & 0.103 & & \\
& Education level & -0.144 & & \\
& Family Size & $-0.552^{* *}$ & & \\
& Duration of Residence & 0.255 & & \\
& Perception & 0.034 & \\
\hline
\end{tabular}

Linear regression analysis was performed between per capita fuelwood consumption and family size, as dependent and independent variables, respectively (Fig. 4); this was significant with F-value of 17.44. Family size explained about $30 \%\left(\mathrm{R}^{2}=0.31\right)$ of the fuelwood consumption and with an increase of one family member the daily per capita fuelwood consumption decreased by $0.09 \mathrm{~kg}$. Plotting the per capita daily fuelwood consumption against the family size also reflects the result of linear regression. Thus, the relationship between family size and fuelwood consumption showed a decreasing trend of fuelwood consumption with increased family size.

\section{Discussion}

\section{A. Fuelwood Consumption and Source}

The mean of daily fuelwood consumption per capita was $3.2 \mathrm{~kg}$ (1168 kg/person/year) which is comparatively higher than found in similar studies. A study conducted in seven locations in the northern Brazilian Atlantic Forest found fuelwood consumption of $961( \pm 778)$ $\mathrm{kg} /$ person/year for people exclusively depending on fuelwood for cooking (Specht et al., 2015); and in rural hilly areas in Karnataka, India, fuelwood consumption was $744 \mathrm{~kg} /$ person/year (Ranganathan et al., 1993).

Settlements of the Teknaf Peninsula are scattered in and around the local forests and the officially protected forest area is practically open for small-scale activities such as fuelwood collection. Since local people have no alternative sources of energy for cooking, most are directly dependent on forests. Cow dung, charcoal and jute sticks are widely used in other rural areas in Bangladesh for cooking fuel but not commonly in
Teknaf. Liquid petroleum gas and electric heaters are too costly for these people. As a result, due to poverty, the lack of alternative fuels and ample availability of fuelwood inside the nearby forest, the local people have no fuel choice other than fuelwood from the forest. For these reasons, fuelwood consumption in the Teknaf Peninsula is relatively higher than reported for other areas. Fuelwood is mainly collected from the forests by the local people themselves and it is very common for people in Teknaf to enter the forest and cut trees for fuelwood. Some poor people in the locality sell harvested fuelwood as their means of livelihood. As a result, even when people buy fuelwood from the local markets, it actually comes from the protected forest area.

Apart from forest fuelwood, local people also collect fuelwood from their homestead; however, this proportion $(37 \%)$ is quite low compared to forest fuelwood (63\%). When the percentage of fuelwood from the forest increased, the consumption of fuelwood also increased (Fig. 2). Fuelwood from homesteads can significantly contribute to decreasing the total consumption from forests and so reduce pressure on local forests.

\section{B. Socioeconomic Characteristics}

Socioeconomic characteristics give a summary of the situation of local people in the study area. The mean age of $\mathrm{HH}$ head was 34.3 years and heads of small family were on average younger than those of large families. This is because young people separate from their old family and start to live on their own.

The mean of schooling was 2.07 years, which was nearly half of the national mean of 5.1 years (BBS, 2011). This data reflects the poor education situation of 
the Teknaf Peninsula. In this study, large families had nearly twice the income of small and medium families. In rural areas of Bangladesh, family members playa vital role in the annual income of HHs. However, the large families in this study had a relatively poor education level. Mean family size (5.3) in the Teknaf Peninsula was greater than the national mean of 4.50 .

Perception towards fuelwood extraction and environmental degradation was similar among the three size categories. The mean score reflects that the people were neutral about fuelwood extraction and environmental degradation. Lower awareness, education and high poverty results in a neutral perception of the people.

\section{Factors Affecting Fuelwood Consumption}

Among the considered variables, only family size had a significant correlation (this was also negative) with fuelwood consumption (Table 4): With the increase of family size the per capita fuelwood consumption decreased. Other studies have indicated different factors are also responsible for fuelwood consumption. The relationship between poverty and fuelwood dependency has been documented in Brazil and other countries at local scales (Hiemstra van der Horst and Hovorka, 2009; Matsika et al., 2013; Top et al., 2006). de Mederios et al., (2012) found that socioeconomic characteristics of rural communities in the same region explained up to $31 \%$ of fuelwood consumption, with monthly income the most important. We also found that a socioeconomic characteristic (i.e., family size) was related to fuelwood consumption: with an increase of one family member, the per capita fuelwood consumption decreased about $0.09 \mathrm{~kg}$. But the unique point is among the social characteristics only family size influences the fuelwood consumption. So either rich or poor, educated or noneducated the fuelwood consumption is same for every household except if the family size differs. This also points to the over dependency of fuelwood which is a threat to the existing forests.

\section{Impact of Fuelwood Consumption on Forest and Climate}

The Teknaf Peninsula has 11,615 ha of protected forest area. Currently this forest experiences no largescale disturbance such as wood trade or encroachment; however, disturbance at small scales such as fuelwood collection and other subsistence activities are affecting the forest. As a result, during 1989-2009 the forest area decreased about 45\% (CGEIS, 2011).

In contrast to the decrease in forest land, the population of Teknaf Upazilahas increased at an annual rate of nearly $2.76 \%$ at the same time and the population is now 260,000 (BBS, 2011). Figure 4 shows the trend of forest decrease and population increase of Teknaf during the last few decades. The increase of population exerts pressure on the decreasing forest. We found that on average a person consumed $1168 \mathrm{~kg}$ of fuelwood annually and the total annual consumption of the Teknaf Peninsula was about 300,000 tons (considering a total population of 260,000). Almost all of this large amount of fuelwood is from the local forest. In this study, fuelwood consumption was compared using Above Ground Wood Biomass Production (AGWP), which is all living biomass above the soil including stem, stump, brunches, bark, seeds and foliage. The highest recorded AGWP in Asia is 23.6 $\mathrm{Mg} / \mathrm{ha} /$ year (Paoli and Curran, 2007).

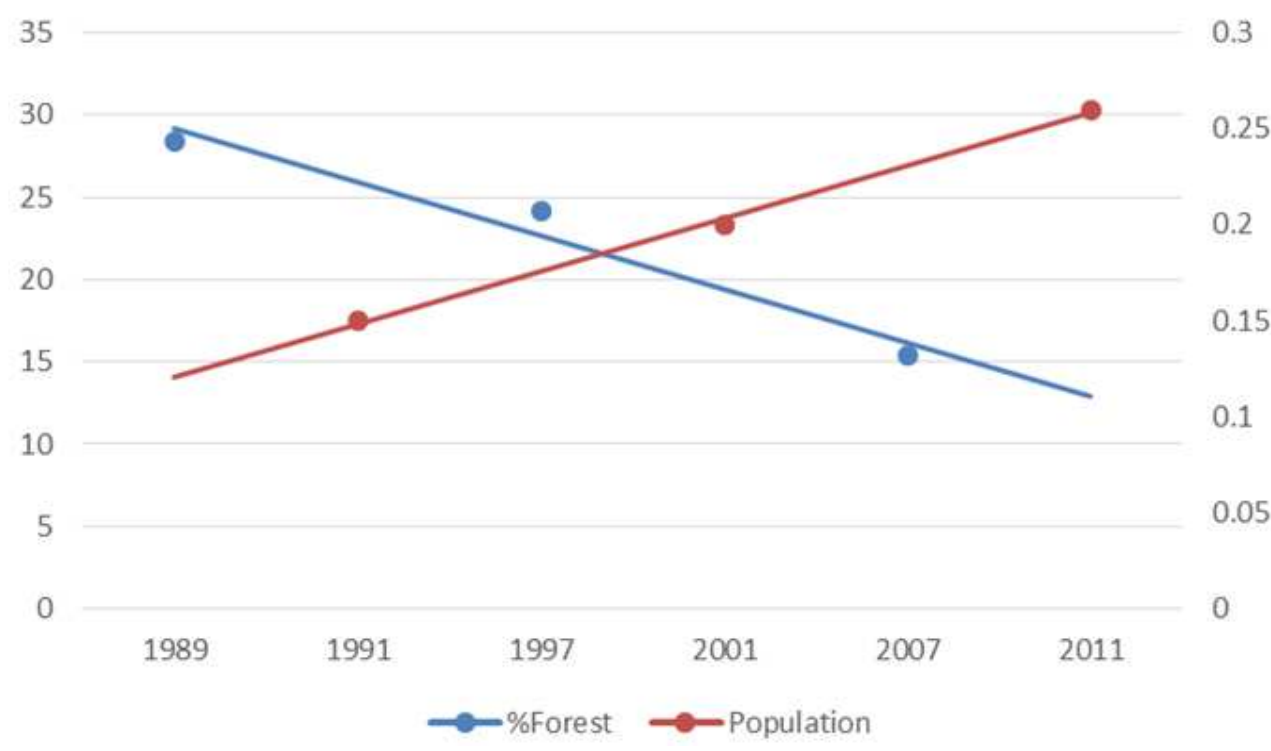

Fig. 5. Forest land and population trend in Teknaf (Source: 26, 27) 
In this study, fuelwood need was determined based on $\mathrm{HH}$ fuelwood consumption. To compare the fuelwood, need and its supply from forest, productivity of the Teknaf forest was considered as the highest AGWP in Asia. This was because using the highest possible productivity gives the likely maximum supply of fuelwood. This calculated AGWP of the 11,615 ha of forest land of Teknaf was 274,114 tons. If we consider that all the biomass production is consumed by the local people, this represents nearly $90 \%$ of the total fuelwood consumption. Thus it can be roughly estimated that all of the forest production of the Teknaf Peninsula is insufficient to meet the fuelwood demand. People solely depend on local forests for fuelwood but they also depend on other forest products such as building materials (houses and boats), agriculture operation and fodder. All these factors exert pressure on local forests and result in destruction of the forest. The trends for forest land and population indicate that the situation will become more critical (Fig. 5). The current decrease of about $45 \%$ of forest will continue if proper measures are not taken quickly. On the other parts of the world, harvesting fuelwood may not be a threat to the forest but in Teknaf peninsula harvesting fuelwood is threatening the existence of forests and also hindering the regeneration of the forest.

Fuelwood consumption in Teknaf is around 300,000 tons/year. Burning this amount of fuelwood has impact on the climate. Besides deforestation, fuelwood is also responsible for the emission of excessive amount of Green House Gases (GHGs). Considering the following conversion factors (Smith et al., 2000), $1 \mathrm{~kg}$ fuelwood burning causes emission of $1.518 \mathrm{~kg}$ Carbon, $1.406 \mathrm{~kg}$ $\mathrm{CO}_{2}, 0.084 \mathrm{~kg} \mathrm{CH}_{4}$ and $0.028 \mathrm{~kg} \mathrm{~N}_{2} \mathrm{O}$ in Teknaf 300,000 ton fuelwood burning causes 455,400 ton Carbon, 25,000 ton $\mathrm{CH}_{4}$ and 8,400 ton $\mathrm{N}_{2} \mathrm{O}$ emission.

\section{Conclusion}

We quantified the amount of $\mathrm{HH}$ fuelwood consumption in a coastal village in Bangladesh, where the hilly forest ecosystem is facing threats due to subsistence activities of the local poor people. The annual fuelwood consumption per capita was 1168 tonnes, which is higher than in other parts of the world. Among basic socioeconomic factors such as age, education, income, family size and $\mathrm{HH}$ area, only family size was related to $30 \%$ of fuelwood consumption. However, there is scope for further studies as proximity from forest, plant species and types of oven influence $\mathrm{HH}$ fuelwood consumption in other parts of the world. To cope with the threat of climate change, protecting forests is vital but poor people are dependent on forests for their daily needs. This study will help to design forest conservation by ensuring sustainable resource use of forests in the Teknaf Peninsula as well as in Bangladesh generally.

\section{Acknowledgement}

This work was supported by JSPS KAKENHI (Grantin-Aid for Scientific Research A) Grant No. 15H02612.

\section{Author's Contributions}

Ullah SM Asik: Conception, design, acquisition, analysis and inerpretation of data and drafting the article.

Tani Masakazu: Critical reviewing and final approval of the version to be submitted.

\section{Ethics}

This article is original and contains unpublished material. The corresponding author confirms that all of the other authors have read and approved the manuscript and no ethical issues involved.

\section{References}

Alam, M.F., M.Z. Uddin and M.A. Hasan, 2012. Evaluation of plant biodiversity in Teknaf Wildlife Sanctuary. Bangladesh LAP Lambert Academic Publishing, Germany.

Arnold, M. and R. Persson, 2003. Reassessing the fuelwood situation in developing countries. Int. Forest Rev., 5: 379-383. DOI: $10.1505 /$ IFOR.5.4.379.22660

BBS, 2011. Preliminary report of census BBS. Bangladesh Bureau of Statistics, Ministry of Planning, Government of the People's Republic of Bangladesh, Dhaka.

BMD, 2014. Weather report. Bangladesh Meteorological Department, Government of People's Republic of Bangladesh.

Bhatt, B.P. and M.S. Sachan, 2004. Firewood consumption along an altitudinal gradient in mountain villages of India. Biomass Bioenerg, 27: 69-75. DOI: 10.1016/j.biombioe.2003.10.004

Bond, T. and H. Sun, 2005. Can reducing black carbon emissions counteract global warming? Environ. Sci. Technol., 39: 5921-5926. DOI: 10.1021/es0480421

Bouget, C., A. Lassauce and M. Jonsell, 2012. Effects of fuelwood harvesting on biodiversity-a review focused on the situation in Europe. Can. J. Forest Res., 42: 1421-1432. DOI: 10.1139/x2012-078

CGEIS, 2011. Center for Environment and Geographic Information System. Dhaka, Bangladesh.

de Mederios, P.M., T.C. da Silva, A.L.S. de Almeida and U.P. de Albuqueraque, 2012. Socio-economic predictors of domestic wood use in an Atlantic forest area (north-east Brazil): A tool for directing conservation efforts. Int. J. Sust. Dev. World, 19: 189-195. DOI: 10.1080/13504509.2011.614288 
Hiemstra van der Horst, G. and A.J. Hovorka, 2009. Fuelwood: The "other" renewable energy source for Africa? Biomass Bioenerg, 33: 1605-1616. DOI: 10.1016/j.biombioe.2009.08.007

IEA, 2010. Energy poverty: How to make modern energy access universal? International Energy Agency, World Energy Outlook, Paris.

Jetter, J.J. and P. Kariher, 2009. Solid-fuel household cook stoves: Characterization of performance and emissions. Biomass Bioenerg, 33: 294-305. DOI: 10.1016/j.biombioe.2008.05.014

Likert, R., 1932. A technique for the measurement of attitudes. Arch. Psychol., 22: 1-55.

Madubansi, M. and C.M. Shackleton, 2006. Changing energy profiles and consumption patterns following electrification in five rural villages, South Africa. Energy Policy, 34: 4081-4092. DOI: 10.1016/j.enpol.2005.10.011

Matsika, R., B.F.N. Erasmus and W.C. Twine, 2013. A tale of two villages: assessing the dynamics of fuelwood supply in communal landscapes in South Africa. Environ. Conserv., 40: 71-83. DOI: $10.1017 / \mathrm{S} 0376892912000264$

Myers, N., R.A. Mittermeier, C.G. Mittermeier, G.A.B. da Fonseca and J. Kent, 2000. Biodiversity hotspots for conservation priorities. Nature, 403: 853-858. DOI: $10.1038 / 35002501$

Osei, W.Y., 1993. Woodfuel and deforestation-answers for a sustainable environment. J. Environ. Manage., 37: 51-62. DOI: 10.1006/jema.1993.1004

Paoli, O.L. and L.M. Curran, 2007. Soil nutrients limit fine litter production and tree growth in mature lowland forest of southwestern Borneo. Ecosystem, 10: 503-518. DOI: 10.1007/s10021-007-9042-y

Peres, C.A., T.A. Gardner, J. Barlow, J. Zuanon and F. Michalski et al., 2010. Biodiversity conservation in human-modified Amazonian forest landscapes. Biol. Conserv., 143: 2314-2327. DOI: $10.1016 /$ j.biocon.2010.01.021

Ramanathan, V. and G. Carmichael, 2008. Global and regional climate changes due to black carbon. Nat. Geosci., 1: 221-227. DOI: 10.1038/ngeo156
Ranganathan, V., S.R. Subba and G.S. Praddu, 1993. Demand and supply of fuelwood in Karnataka. (unpublished) For the Forest Department, Government of Karnataka. Indian Institute of Management (II M), Bangalore.

Ruger, N., G. Williams-Linera, W.D. Kissling and A. Huth, 2008. Long-term impacts of fuelwood extraction on a tropical montane cloud forest. Ecosystems, 11: 868-881. DOI: 10.1007/s10021-008-9166-8

Smith, K.R., R. Uma, V.V.N. Kishore, J. Zhang and V. Joshi et al., 2000. Greenhouse implications of household stoves: An analysis for India. Annual Rev. Energy Environ., 25: 741-763.

DOI: 10.1146/annurev.energy.25.1.741

Sovacool, B.K. and I.M. Drupady, 2011. Summoning earth and fire: the energy development implications of Grameen Shakti (GS) in Bangladesh. Energy, 36: 4445-4459. DOI: 10.1016/j.energy.2011.03.077

Specht, M.J., S.R.R. Pinto, U.P. Albuquerque, M. Tabarelli and F.P.L. Melo, 2015. Burning biodiversity: fuelwood harvesting causes forest degradation in human-dominated tropical landscapes. Global Ecol. Conserv, 3: 200-209. DOI: 10.1016/j.gecco.2014.12.002

Tani, M., M.Z. Rahman, A. Rahman, K. Asahiro and S. Akter, 2011. Deforestation by daily activities in the Teknaf Peninsula, Bangladesh. Proceedings of the International Conference on Environmental Aspects of Bangladesh, (EAB; 11), pp: 74-74.

Top, N., N. Mizoue, S. Ito, S. Kai, T. Nakao and S. Ty, 2006. Re-assessment of woodfuel supply and demand relationships in Kampong Thom Province, Cambodia. Cambodia Biomass Bioenerg, 30: 134-143. DOI: 10.1016/j.biombioe.2005.11.008

World Bank, 2015. Washington (DC): World Bank rural population indicators c2016.

WHO, 2006. Fuel for life: Household energy and health. World Health Organization, Geneva. 